\title{
Design and experiment of a six-row air-blowing centralized precision seed-metering device for Panax notoginseng
}

\author{
Qinghui Lai ${ }^{1}$, Kai Sun ${ }^{1}$, Qingxu Yu ${ }^{2}$, Wei Qin ${ }^{1}$ \\ (1. Faculty of Agriculture and Food, Kunming University of Science and Technology, Kunming 650500, China; \\ 2. Nanjing Institute of Agricultural Mechanization, Ministry of Agriculture and Rural Affairs, Nanjing 210014, China)
}

\begin{abstract}
Panax notoginseng is grown mainly in Yunnan Province. Under the present high-density planting patterns for the plant, to solve the problems of a high rate of seed damage and the inability to use a traditional single air-blowing metering device, this paper designs a six-row air-blowing centralized precision seed-metering device for $P$. notoginseng to realize mechanized precision seeding of this species. This paper describes the working principle of the seed-metering device, and the main structural parameters are determined by combining theoretical calculations with simulation analysis. A mechanics model of the seed filling, cleaning and pressing processes of the seed-metering device was constructed. The seeds of $P$. notoginseng in Yunnan Province were selected as experimental subjects. An experimental study on the seed-metering performance of the seed-metering device was carried out using the quadratic rotation orthogonal combination test method. The outlet pressure of the air nozzle, forward velocity and cone angle of the hole were selected as test factors. Mathematical models of the grain spacing qualified index, miss index, multiple index and the coefficient of variation of the row displacement consistency were established to analyze the order of factors affecting indicators. Through parameter optimization, the optimum combination of parameters was determined as follows: the cone angle of the hole is $50^{\circ}$, the forward velocity is less than $0.73 \mathrm{~m} / \mathrm{s}$, and the outlet pressure of the air nozzle is $0.32-0.52 \mathrm{kPa}$. The qualified index of grain spacing is higher than $94 \%$, the miss index is less than 3\%, the multiple index is less than 5\%, and the coefficient of variation of the row displacement consistency is less than 5\%. The test results are essentially consistent with the optimization results. The metering device meets the requirements of precision seeding of $P$. notoginseng. This study provides a basis for the design of a six-row air-blowing centralized precision seed-metering device for $P$. notoginseng.
\end{abstract}

Keywords: Panax notoginseng, air blowing, seed-metering device, optimization design, air distribution mechanism DOI: $10.25165 /$ j.ijabe.20201302.5161

Citation: Lai Q H, Sun K, Yu Q X, Qin W. Design and experiment of a six-row air-blowing centralized precision seed-metering device for Panax notoginseng. Int J Agric \& Biol Eng, 2020; 13(2): 111-122.

\section{Introduction}

Because the seeds of Panax notoginseng are irregular and variably sized, the seed coat is easily damaged during mechanical processing. A mechanical seed-metering device cannot meet the requirement of precise and quantitative seeding of $P$. notoginseng because of its strict requirements with respect to the shape and size of seeds and the low operation speed. Therefore, in actual large-scale production, mechanical metering devices have gradually been replaced by pneumatic metering devices ${ }^{[1]}$.

At present, the air-blowing metering device is represented by the Aeromat-II air-blowing seed-metering device produced by the West German Carl Baker Company ${ }^{[2,3]}$. This device can meet different crop seeding requirements by adjusting the air pressure values. Yazgi et al. ${ }^{[4,5]}$ analyzed the effects of the operating speed and hole number on the seeding uniformity in the operation of an air-suction metering device. Zulin et al. ${ }^{[6]}$ improved the

Received date: 2019-05-27 Accepted date: 2020-03-14

Biographies: Kai Sun, Master candidate, research interests: agricultural mechanization engineering, Email: skmust@163.com; Qingxu Yu, Master, Assistant Engineer, research interests: agricultural mechanization engineering, Email: 511359357@qq.com; Wei Qin, Master candidate, research interests: agricultural mechanization engineering, Email: 1240672079@qq.com.

*Corresponding author: Qinghui Lai, $\mathrm{PhD}$, Associate Professor, research interests: agricultural mechanization engineering. Mailing address: Kunming University of Science and Technology, Kunming 650500, China. Tel: +86-13529280568, Email: laiqinghui007@163.com. pneumatic metering device and studied the effects of the linear velocity of the planter plate and the air velocity on the performance of the metering device.

Domestic research on air-blowing metering devices has been based mainly on the Aeromat-II air-blowing seed-metering device ${ }^{[7,8]}$. Ma et al. ${ }^{[9,10]}$ carried out experimental research on cone hole models and seed-metering devices using dimension theory and revealed the filling principle of air-blowing seed-metering devices. Hu et al. ${ }^{[11,12]}$ analyzed the influence of the cone hole parameters on seed-metering quality using the basic principles of fluid mechanics. Yu et al. ${ }^{[13,14]}$ used a uniform design method to carry out atmospheric pressure tests on soybean air-blowing metering devices. A regression equation and optimum structural parameters were obtained. Tang et al. ${ }^{[15]}$ compared the different pore structures of air-blowing precision metering devices for hybrid rice and verified that the elliptic cone-shaped pore metering effect was the best. Liu et al. ${ }^{[16]}$ obtained the optimum blowing pressure range suitable for maize sowing through the combination of a bench test and a field test. Liao et al. ${ }^{[17]}$ designed a precision pneumatic seed-metering device for rapeseed and studied the influence of related parameters on the seed-metering uniformity. Li et al. ${ }^{[18,19]}$ developed a pneumatic drum rapeseed-metering device that allows multiple rows and studied the influence of related factors on the metering performance.

In summary, the air-blowing metering device is currently mainly a single-row metering device, but the seeding density of 
P. notoginseng is high, and the seed spacing is small. Therefore, using a single-row metering device cannot meet the requirements of precision seeding of $P$. notoginseng ${ }^{[20]}$. An air-blowing metering device is used mostly for soybean, maize and other high-density crops, while the optimum range of the air-blowing pressure is small when planting $P$. notoginseng, which requires consistency of the air-blowing pressure.

Therefore, to meet the agronomic requirements, reduce air-blowing pressure and improve the quality of seeding, this paper designed a six-row air-blowing centralized precision seed-metering device for $P$. notoginseng. To provide a reference for the design of the six-row air-blowing centralized precision seed-metering device for $P$. notoginseng, the effect of the outlet pressure of the air nozzle, forward speed and taper of the seed cell on the seed-metering performance and the optimum combination of parameters were explored.

\section{Structure and working principle of the seed-metering device}

The structure of the seed-metering device is shown in Figure 1. The working process of the metering device can be divided into four areas: a seed-filling area, seed-cleaning area, seed-protection area and seed-unloading area. When the metering device is working, the fan is connected to the air distributor and directs high-speed air flow through the air nozzles. With the counterclockwise rotation of the metering wheel, the seeds of $P$. notoginseng are separated from the population and fall into the hole under the combined action of their own gravity, filling force and airflow. When the metering rotation reaches the seed-cleaning area, the seed-cleaning and seed-pressing processes are completed under the action of high-speed airflow. Under the action of hole-type and seed-guarding boards, $P$. notoginseng seeds are rotated into the seed-unloading area along with the seed-wheel. Under the combined action of gravity, centrifugal force and seed-unloading torsional spring, seeds fall into the sowing area, and the seed-metering operation is completed.
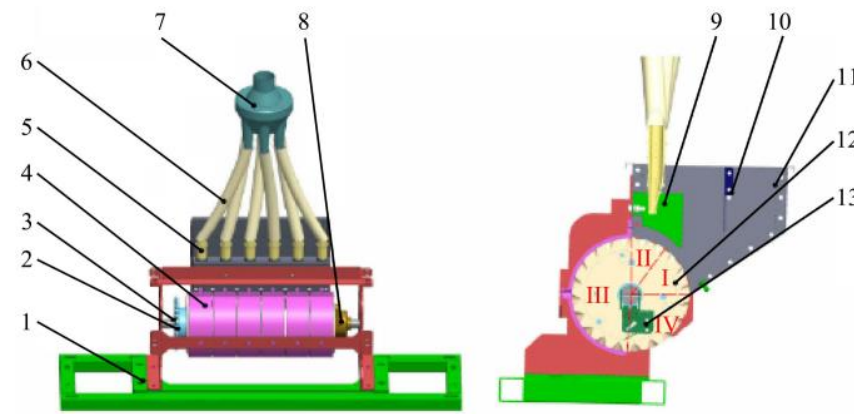

1. Frame 2. Chain wheel 3. Seeding axis 4. Seed-guarding board 5. Air nozzle 6. Air tube 7. Air allotter 8. Bearing 9. Air isolation plate 10. Seed-retaining plate 11. Seedbox 12. Seed-wheel 13. Torsion spring seed-pushing device I. Seed-filling area II. Seed-cleaning area III. Seedguarding area IV. Seed-unloading area

Figure 1 Structure diagram of the seed-metering device

\section{Key component design}

\subsection{Air allotter of the seed-metering device}

\subsubsection{Working principle of the air allotter}

The air separation system of the six-row air-blowing centralized precision seed-metering device for $P$. notoginseng is shown in Figure $2^{[21]}$. It is composed mainly of an air allotter, air nozzle and air supply soft tube. The air allotter is composed of one inlet end and six outlets. The inlet is connected to the fan, and the outlet is connected to each row of air nozzles through the air supply soft tube. When the seed-metering device is working, the air flow from the fan transitions to a high-speed flow moving through the air allotter and exits the air nozzle to complete the seed-cleaning process. In this process, the pressure loss includes the pressure loss along the air supply soft tube and the local pressure loss at the air allotter. Because the distance between the fan and the metering device cannot be changed, the pressure loss along the air supply soft tube cannot be reduced. The local pressure loss is greatly affected by the structure shape, so the pressure loss of the entire machine can be reduced by optimizing the air allotter mechanism.

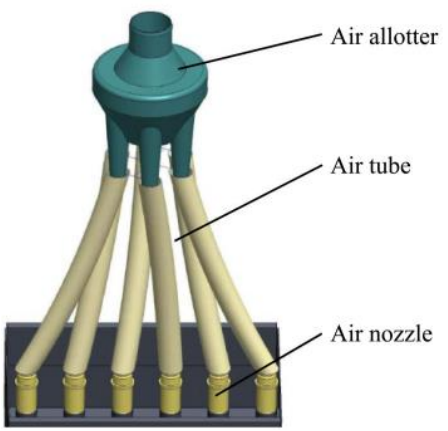

Figure 2 Schematic diagram of the air allotter

According to fluid mechanics ${ }^{[22]}$, the local pressure loss of a simple structure can be calculated, but the local pressure loss of a complex structure is not the superposition of the pressure losses of a simple structure. With this type of irregular structure, the outlet pressure of each point can be measured by means of experiments only, which allows calculation of the local pressure loss coefficient. In this paper, the pressure input value and outlet pressure of the air separator are measured by means of a simulation test, and the shape and structure parameters of the air allotter with small pressure loss and uniform air distribution are obtained by a simulation optimization step by step.

\subsubsection{Three-dimensional structure design of the air allotter}

According to the basic principle of fluid mechanics and on the basis of the air allotter of common planters at home and abroad, three types of air allotters with different structure types, I, II and III, shown in Figure 3, were preliminarily designed. Type I is a radial uniform air allotter commonly used in pneumatic seeders. The inlet is located in the middle of one side of the air allotter, and six outlets are evenly distributed on the outer cylinder wall of the air allotter. Type II is an evenly distributed axial air allotter without an inner cone. The inlet is on one side of the air allotter, and six outlets are evenly spaced on the other side of the air allotter. On the basis of type II, type III adds a conical table on the inside of the air allotter to form an evenly distributed axial air allotter with an inner cone.

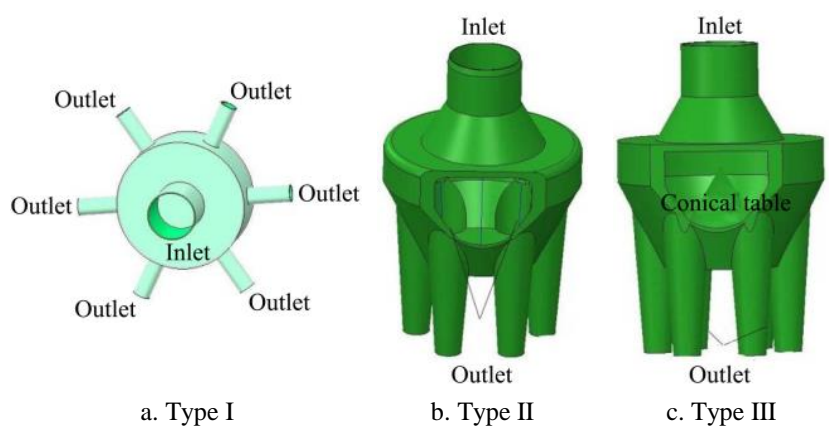

Figure 3 Schematic diagram of three different structures of air allotters 
To explore suitable structures of the air allotter, a flow field analysis of the three different structures of the air allotter is carried out using flow field simulation. The working performance of an air-blowing centralized precision seed-metering device is affected strongly by the pressure stability of the blowing air and the uniformity of each air flow row. Therefore, the average pressure ratio of the inlet and outlet and the coefficient of variation of each row's pressure consistency are selected as evaluation indexes for simulation analysis. The larger the average pressure ratio of the inlet and outlet, the smaller is the pressure loss ratio. The lower the coefficient of variation of each row pressure consistency, the better is the working performance of the seed-metering device. To obtain reliable simulation results, this paper sets up the same inlet area and the same total area of the outlet and maintains the same inlet pressure. The average pressure ratio of the inlet and outlet and the coefficient of variation of each row's pressure consistency can be expressed as

$$
\bar{P}=\frac{\sum_{i=1}^{n} P_{i}}{n}
$$

$$
\begin{gathered}
\sigma_{1}=\frac{\bar{P}}{P_{\lambda}} \times 100 \% \\
\sigma_{2}=\sqrt{\frac{\sum_{i=1}^{n}\left(P_{i}-\bar{P}\right)^{2}}{n}} \\
C_{v}=\frac{\sigma_{1}}{\bar{P}} \times 100 \%
\end{gathered}
$$

where, $P_{\lambda}$ is the inlet pressure; $P_{i}$ is each row's outlet pressure ( $i=$ $1,2,3 \ldots 6) ; n$ is the number of outlets; $\bar{P}$ is average outlet pressure; $\sigma_{2}$ is the standard deviation of each row's outlet pressure; and $C_{v}$ is the coefficient of variation of each row's pressure consistency.

\subsubsection{Preliminary flow field analysis of air allotters}

This paper applies the software Fluent to analyze the flow field of three types of air allotters. Pretest results show that the actual working pressure of air blowing for a single row ranges from $0.2 \mathrm{kPa}$ to $0.5 \mathrm{kPa}$. In Fluent software, the inlet pressure is set to $2 \mathrm{kPa}$, and the outlet pressure is set to standard atmospheric pressure for simulation calculation. The simulation results of the pressure nephogram are shown in Figure 4.

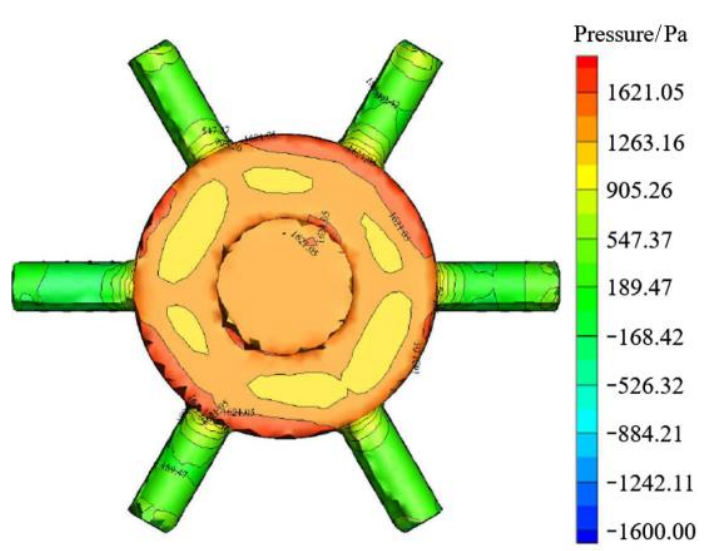

a. Pressure nephogram of type I air allotter

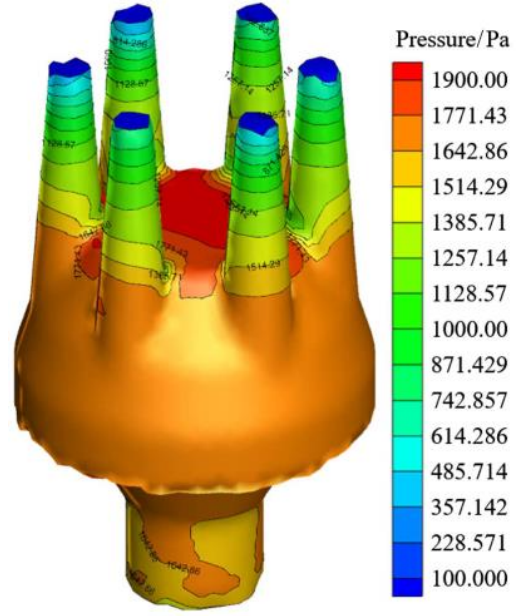

b. Pressure nephogram of type II air allotter

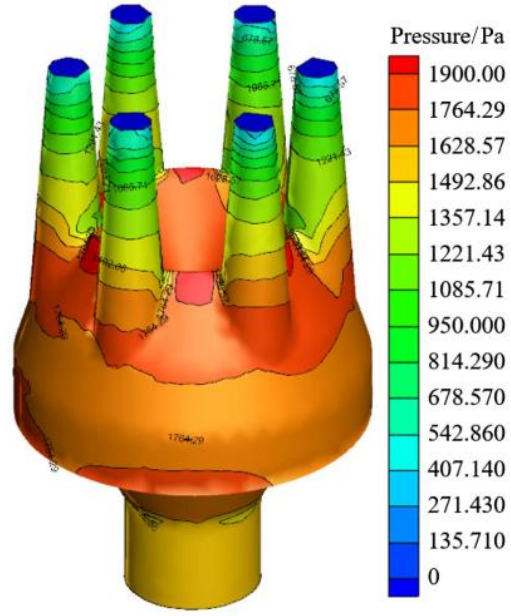

c. Pressure nephogram of type III air allotter

Figure 4 Pressure maps of the gas separation mechanisms

By reading the inlet and outlet pressures, the average pressure ratio of the inlet and outlet and the coefficient of variation of each row pressure consistency are calculated. The results are shown in Table 1. The average pressure ratio of the inlet and outlet of the type III air allotter is the largest of the allotters, indicating that the outlet pressure of this allotter type is the largest and the pressure loss is the smallest when the inlet pressure, the outlet area and the inlet area are the same. In addition, the coefficient of variation of each row's pressure consistency is the smallest of the allotters, showing the best uniformity of air flow. This type is the most ideal form of these three mechanisms.

Table 1 Flow simulation results of the three types of air allotters

\begin{tabular}{cccc}
\hline Air allotter & $\bar{P} / \mathrm{Pa}$ & $\sigma_{1} / \%$ & $C_{\nu} / \%$ \\
\hline Type I air allotter & 154.98 & 8.12 & 17.69 \\
Type II air allotter & 219.98 & 11.54 & 14.13 \\
Type III air allotter & 298.50 & 15.27 & 10.81 \\
\hline
\end{tabular}

However, there are still many air vortices in the inlet center and gradual diffuser of the type III air allotter, which is the main reason for the local pressure loss. The low flow velocity at the corner of the wall readily causes uneven pressure at the outlets of all walls. It is necessary to further optimize the key structural dimensions of the air allotter.

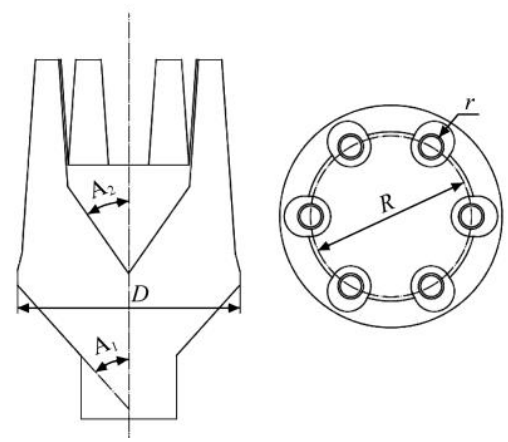

Figure 5 Dividing the mechanism structure size parameter

3.1.4 Orthogonal test of the evenly distributed axial air allotter with an inner cone

As shown in Figure 5, the maximum diameter of the gradual expansion section (D), the angle of the gradual expansion section $\left(\mathrm{A}_{1}\right)$ and the taper of the central cone $\left(\mathrm{A}_{2}\right)$ are selected as test factors, and the average pressure ratio of the inlet and outlet $\left(\sigma_{1}\right)$ and the coefficient of variation of each row's pressure consistency $\left(C_{v}\right)$ are taken as simulation test indexes to carry out three-factor and three-level orthogonal simulation tests for the air allotter. The level of test factors was shown in Table 2 . 
Table 2 Factor level of the simulation test

\begin{tabular}{cccc}
\hline & \multicolumn{3}{c}{ Test factors } \\
\cline { 2 - 4 } Level & $D / \mathrm{mm}$ & $\mathrm{A}_{I} /\left(^{\circ}\right)$ & $\mathrm{A}_{2} /\left(^{\circ}\right)$ \\
\hline 1 & 95 & 30 & 40 \\
2 & 105 & 45 & 50 \\
3 & 120 & 60 & 60 \\
\hline
\end{tabular}

The results of the simulation orthogonal test are shown in Table 3.

Table 3 The results of the simulation test

\begin{tabular}{cccccc}
\hline \multirow{2}{*}{$\begin{array}{c}\text { Test } \\
\text { number }\end{array}$} & \multicolumn{5}{c}{ Test factors } \\
\cline { 2 - 4 } & $\mathrm{A}(\mathrm{D})$ & $\mathrm{B}\left(\mathrm{A}_{1}\right)$ & $\mathrm{C}\left(\mathrm{A}_{2}\right)$ & & $\sigma_{1} / \%$ \\
\hline 1 & 1 & 1 & 1 & 20.89 & 1.61 \\
2 & 1 & 2 & 2 & 21.87 & 2.69 \\
3 & 1 & 3 & 3 & 22.88 & 3.01 \\
4 & 2 & 1 & 2 & 16.85 & 3.81 \\
5 & 2 & 2 & 3 & 17.21 & 4.37 \\
6 & 2 & 3 & 1 & 18.25 & 1.97 \\
7 & 3 & 1 & 3 & 15.01 & 4.97 \\
8 & 3 & 2 & 1 & 16.42 & 2.27 \\
9 & 3 & 3 & 2 & 17.08 & 4.08 \\
\hline
\end{tabular}

3.1.5 Parameter optimization and simulation test verification

Using the software design-export optimization module, the lower limit of the average pressure ratio of the inlet and outlet $\left(\sigma_{1}\right)$ is 20 , and the upper limit of the coefficient of variation of each row's pressure consistency $\left(C_{v}\right)$ is 2.5 . The simulation results are optimized and analyzed according to the range of each factor and the expected standard of the test index. The optimum combination of the optimization results is $\mathrm{A}_{1} \mathrm{~B}_{3} \mathrm{C}_{1}$, and its variability is $98 \%$. Through modification of the structural parameters of the air allotter, the maximum diameter of the gradual expansion section (D) is $95 \mathrm{~mm}$, the angle of the gradual expansion section $\left(\mathrm{A}_{1}\right)$ is $40^{\circ}$, and the taper of the central cone $\left(\mathrm{A}_{2}\right)$ is $45^{\circ}$. Then, the outlet pressure is measured by flow field simulation. The flow field simulation nephogram under these parameters is shown in Figure 6. The average pressure ratio of the inlet and outlet $\left(\sigma_{1}\right)$ is 22.68 , and the coefficient of variation of each row's pressure consistency $\left(C_{v}\right)$ is 0.96 , which is essentially consistent with the optimization results. Therefore, the optimum parameters of the air allotter are determined to be $\mathrm{A}_{1} \mathrm{~B}_{3} \mathrm{C}_{1}$.

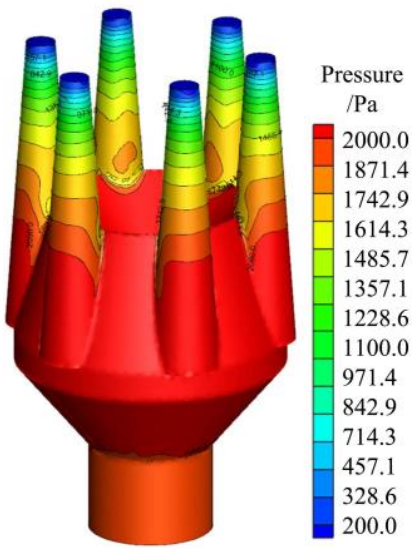

a. Pressure nephogram

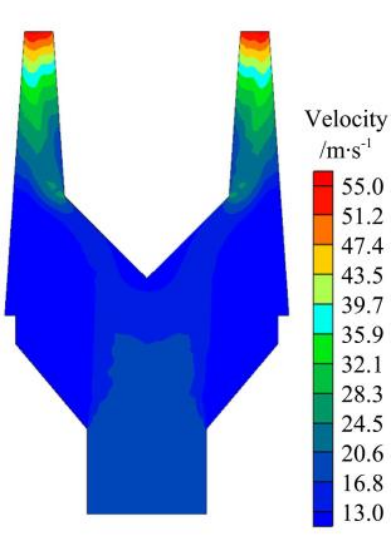

b. Velocity nephogram
Figure 6 Simulation results of the optimal parameter combination

\subsection{Design of the metering wheel}

3.2.1 Structural design of the seeding wheel

The air-blowing centralized precision seed-metering device is composed of a plurality of inlaid single seed-metering wheels. Each single seed-metering wheel has an inlaid tooth structure to ensure that each row of holes is in a straight line, and the seed-metering wheels are fixed by bolts, as shown in Figure 7. The seed-metering wheels on both sides are fixed on the side plate, and there are air outlets to ensure a pressure difference between the inside and outside of the hole.

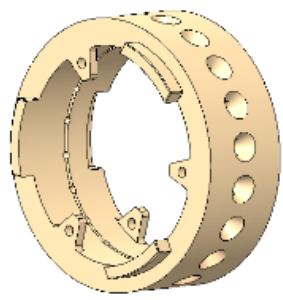

a. Single metering wheel

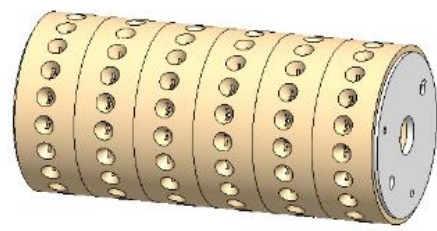

b. Seed-metering wheel assembly
Figure 7 Assembly drawing of the six-row seeding wheel

\subsubsection{Diameter of the metering wheel}

A seed-metering wheel is the key component of a metering device to achieve precision seeding. The structure of the seed-metering wheel determines the structural dimensions of other components. A schematic diagram of the structure of the metering wheel is shown in Figure 8.

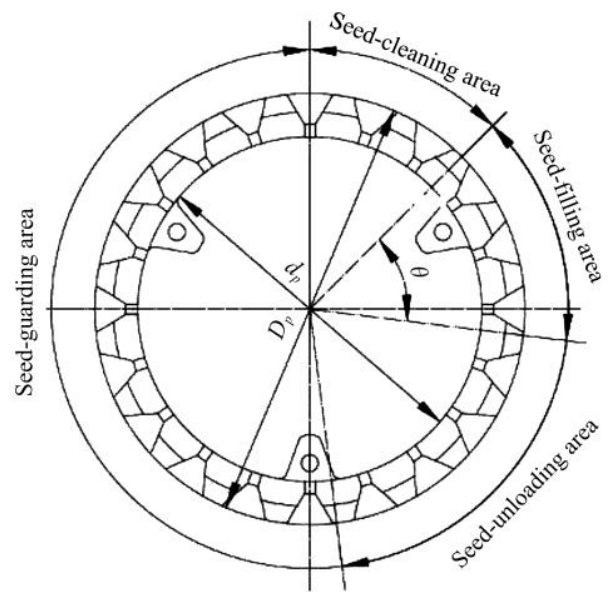

Figure 8 Working sketch of the metering wheel

Equations for the filling time and metering wheel:

$$
\left\{\begin{array}{l}
t=\frac{l_{p}}{v_{q}} \\
l_{p}=\theta \frac{D_{p}}{2} \\
v_{q}=\frac{\pi n D_{p}}{60}
\end{array}\right.
$$

where, $t$ is the filling time; $\theta$ is the radius of the seed-filling area; $D_{p}$ is the diameter of the metering wheel; $v_{q}$ is the linear speed of the seeding wheel, and $n$ is the rotation speed of the metering wheel.

Based on Equation (5), Equation (6) can be obtained:

$$
t=\frac{30 \theta}{\pi n}
$$

Equation (6) shows that the filling time is related to the radius of the seed-filling area $(\theta)$ and the rotation speed of the metering wheel (n), and its diameter does not directly affect the filling effect of the metering wheel. According to the relevant data ${ }^{[23-24]}$, when the plant spacing is fixed, increasing the diameter of the metering wheel can increase the number of holes, reduce the metering speed and improve the quality index of sowing. However, if the 
diameter of the metering wheel is too large, the friction between the seeds and the seed-guarding board will increase, which will increase the damage rate of the seeds and the area of the seed-cleaning area, and the power consumption of the fan will also increase. If the diameter of the metering wheel is too small, the number of holes in the seed-filling area will be reduced, and the filling probability will be reduced. Therefore, according to the seed spacing of $P$. notoginseng, which is $50 \mathrm{~mm}$, the diameter of the metering wheel is $140 \mathrm{~mm}$.

\subsubsection{Hole design}

1) Number of holes

When the operating speed $\left(v_{m}\right)$ and grain spacing $x$ are determined, an increase in the number of holes on the metering wheel can reduce the linear speed of the seeding wheel $\left(v_{q}\right)$, increase the seed-filling time and seed-clearing time, and reduce the multiple index and miss index. However, an excessive number of holes and a shorter arc length between two holes will lead to a higher coefficient of variation of each row's pressure consistency. In this paper, the operating speed $\left(v_{m}\right)$ is less than $10 \mathrm{~km} / \mathrm{h}$, and the linear speed of the seeding wheel $\left(v_{q}\right)$ is less than $0.5 \mathrm{~m} / \mathrm{s}$. According to the data ${ }^{[23]}$, the number of holes should satisfy the following requirement:

$$
\left\{\begin{array}{l}
Q=\frac{v_{q}}{d+\Delta l}=\frac{v_{m}}{x} \\
d+\Delta l \geq 2 d_{\text {max }} \\
Z=\frac{\pi D}{d+\Delta l}
\end{array}\right.
$$

where, $Q$ is the seeding quantity of the seed-metering wheel per second; $x$ is the seed spacing; $d$ is the hole diameter; $\Delta l$ is the hole spacing; $Z$ is the number of holes; and $d_{\max }$ is the maximum seed size.

Equation (7) shows that when the diameter of the metering wheel is $140 \mathrm{~mm}$, the number of holes (Z) ranges from 20.94 to 27.48 , and the number of holes was determined to be 24 .

2) Hole structure

The hole shape of the air-blowing seed-metering device is usually conical, as shown in Figure 9. The diameter of the hole and the diameter of the bottom hole vary according to the seed size. The cone angle of the hole directly affects the seed-filling, seed-clearing and seed-throwing performance.

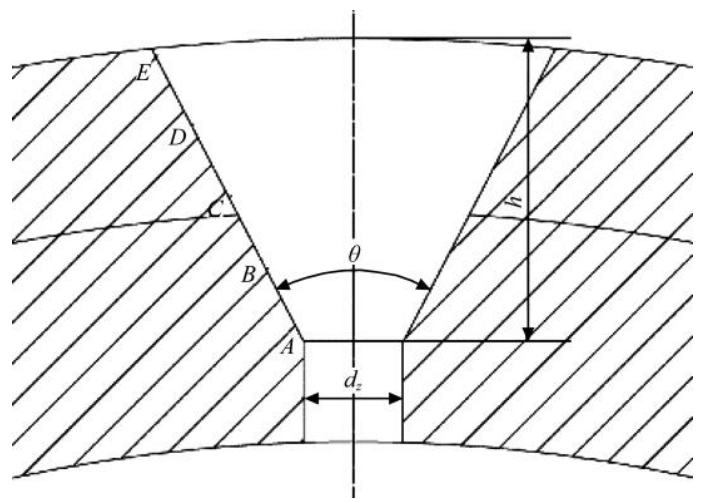

Figure 9 Drawing of the hole structure

In the process of seed cleaning, the cone angle of the hole increases, which is beneficial for the hole sac to seeds. In the process of seed cleaning, the cone angle of the hole increases, which is beneficial for the airflow to remove the surplus seeds in the hole, but too large of an cone angle of the hole will also lead to the airflow to remove all the seeds from the hole, resulting in misseeding. Referring to the data, it can be seen that in the seed-cleaning process, the pressure of the air flow at different points, i.e., at different heights, of the hole wall is different, and the static pressure at point $\mathrm{C}$ is the largest of the pressures at the different points. To ensure single seed pressing in the seed-clearing area and to remove surplus seeds, it is necessary to ensure that a single seed is kept below point $\mathrm{C}$ of the hole, that is, Equation (8) is satisfied. In the process of seed throwing, the cone angle of the hole increases, and the increase in the cone angle of the hole readily causes the seed-protection board to squeeze the seeds and damage the seeds.

$$
\left\{\begin{array}{l}
h \geq d_{p} \\
d_{p} \leq d_{z}+h \tan \frac{\theta}{2}
\end{array}\right.
$$

where, $d_{p}$ is the average seed diameter of $P$. notoginseng; $d_{z}$ is the diameter of the bottom hole; $h$ is the hole depth, and $\theta$ is the cone angle of the hole.

According to the three-axis size distribution of $P$. notoginseng seeds ${ }^{[25]}$, the average diameter of $P$. notoginseng seeds is $5.62 \mathrm{~mm}$. Therefore, the depth of the hole is $10 \mathrm{~mm}$, and the diameter of the bottom hole is $2.5 \mathrm{~mm}$. The cone angle of the hole can be calculated to be in the range of $45^{\circ}-55^{\circ}$.

\subsection{Design of the air nozzle}

The shape, structure size and installation position of the air nozzle have a great influence on the seed-cleaning effect, and it is an important factor to ensure single seed metering of seed-metering devices. The outlet of the air nozzle of the air-blowing metering device is semicircular, and its size should correspond to the size of the hole. In the process of seed cleaning, to ensure that the seeds at the edge of the hole can be cleared by air flow, the outer diameter of the semicircular outlet section of the air nozzle $\left(D_{q}\right)$ should be larger than that of the outer diameter of the hole $\left(D_{x}\right)$. The internal diameter of the outlet section of the air nozzle $\left(d_{q}\right)$ should be smaller than the outer diameter of the outlet section of the air nozzle $\left(D_{x}\right)$.

Therefore, the size of the air nozzle should be satisfied as follows:

$$
\left\{\begin{array}{l}
d_{q} \leq D_{x} \leq D_{q} \\
D_{x}=d_{z}+2 h \tan \frac{\theta}{2}
\end{array}\right.
$$

where, $d_{q}$ is the internal diameter of the outlet section of the air nozzle; $D_{q}$ is the outer diameter of the outlet section of the air nozzle, and $D_{x}$ is the outer diameter of the hole.

According to the cone angle of the hole range, the diameter of the bottom hole and hole depth, the outer diameter of the hole $\left(D_{x}\right)$ ranges from $10.78 \mathrm{~mm}$ to $13.36 \mathrm{~mm}$. Therefore, the internal diameter of the outlet section of the air nozzle $\left(d_{q}\right)$ is $10 \mathrm{~mm}$, and the outer diameter of the outlet section of the air nozzle is $14 \mathrm{~mm}$.

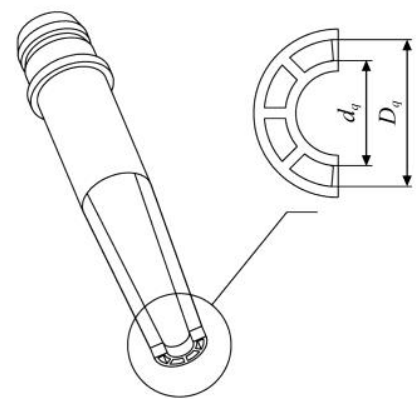

Figure 10 Drawing of the section structure of the air nozzle

As shown in Figure 10, the grid at the outlet of the air nozzle has the functions of collecting, pressurizing and stabilizing the air 
flow and improving the uniformity of the air flow. The number of grids is an important factor affecting the uniformity of air flow and air pressure. In this paper, Fluent is used to simulate the flow of air under different grid densities and to observe the pressure distribution at each point of the hole. The inlet pressure is $0.5 \mathrm{kPa}$, and the air nozzle height is $30 \mathrm{~mm}$. The simulation results are shown in Figure 11. Figure 11a shows the air pressure distribution of the hole in the seed box without a grid. In this case, the air diffusion is considerable, the air pressure is low, the air force cannot concentrate on the hole, and the cleaning effect is not obvious. Figures $11 \mathrm{~b}-11 \mathrm{~d}$ represent one, three and five grid elements, respectively, for the distribution of air pressure in the seed box. The air pressure in Figure $11 \mathrm{~b}$ is concentrated mainly on the edges of the hole, and the pressure is low. The air pressure in Figure 11d is higher than that in Figure 11b, but the distribution of air pressure is not uniform and is discontinuous. The air pressure in Figure 11c is relatively high, and the distribution is uniform and continuous, which is the best condition for the distribution of air pressure in the seed-cleaning chamber. The number of air outlet grid elements is three.

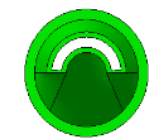

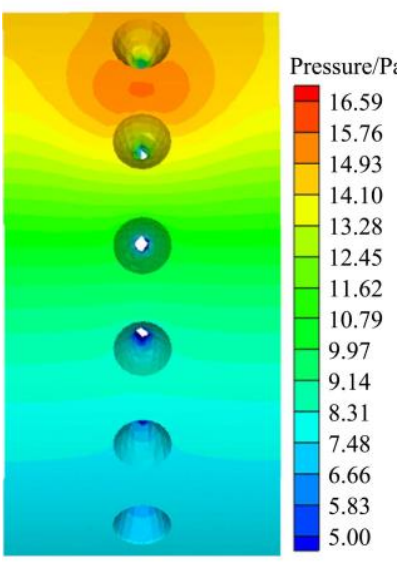

a. No grid
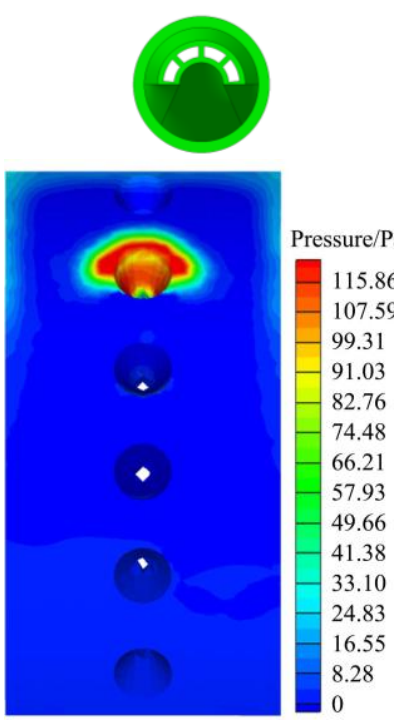

c. Three grid elements

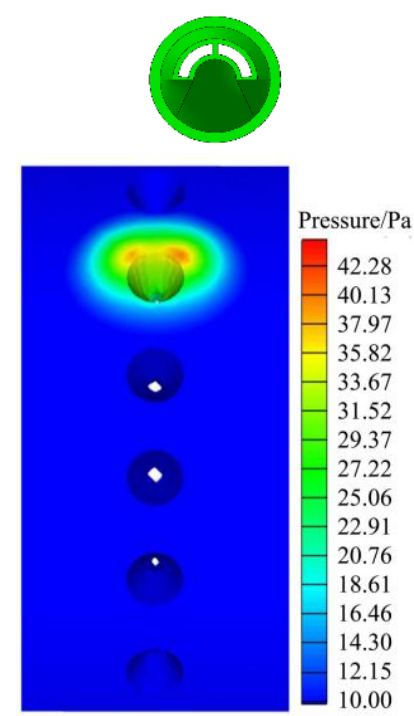

b. One grid element
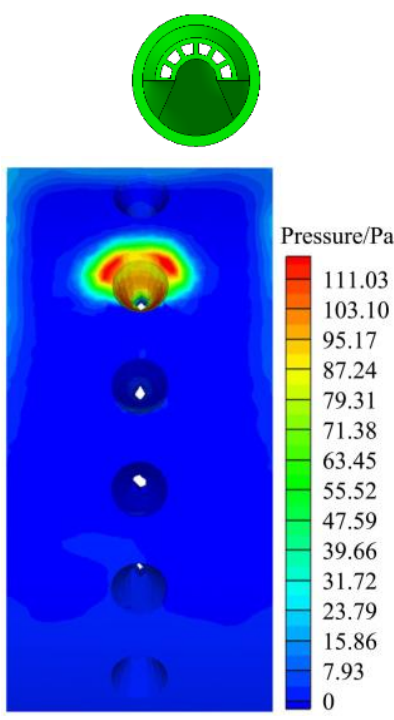

d. Five grid elements
Figure 11 Air pressure distribution in the hole with different numbers of grid elements

\subsection{Design of the seed-pushing device}

To ensure the consistency of seed throwing, it is necessary to add a seed-pushing device in the metering wheel to push out quickly any seeds stuck in the hole ${ }^{[26]}$. In this paper, a seed-pushing device is designed, as shown in Figure 12.

The seed-pushing device is composed mainly of upper and lower fixing plates, bolts and seed-pushing torsion springs. In the radial drilling of the seed-metering axis, the seed-pushing device is connected to the seed-metering axis by bolts, and the upper and lower fixing plates are connected to two groups of internal hexagonal bolts. One end of the seed-pushing torsion spring is fixed on the long groove of the lower fixing plate by bolts. Moving the position of the bolt on the long groove can adjust the thrust of the seed-pushing torsion spring on the seeds. The lower fixing plate has three circular holes, and the center of the torsion spring is fixed on the circular holes of different heights to adjust the thrust angle of the torsion spring. The angle of the torsion spring is $60^{\circ}$. When installed, the springs are clamped on the seed-pushing groove inside the seed-metering wheel.
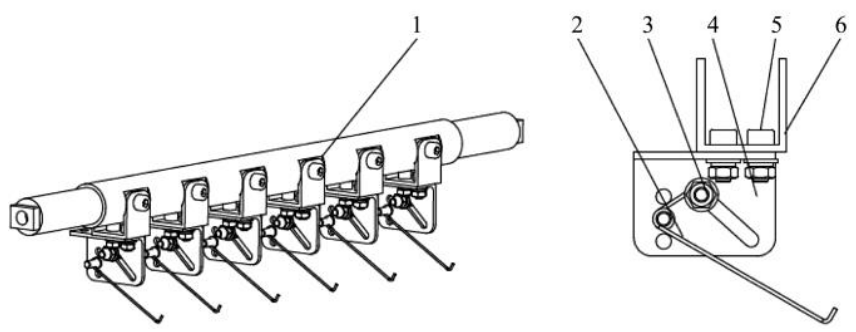

1. Seed-metering axis 2. Seed-pushing torsion spring 3. Bolt 4. Lower fixing plates 5. Internal hexagonal bolts 6 . Upper fixing plates

Figure 12 Schematic diagram of the seed-pushing device

\section{Mechanics analysis of the working process}

Seed filling depends mainly on gravity and seed population support of seeds in the seed-filling area. In the seed-cleaning area, there is relative movement between the seeds and airflow. The force acting on seeds in the flow field includes mainly the drag force and pressure gradient force ${ }^{[27]}$. According to Stokes' theorem, the drag force $\left(F_{D}\right)$ and the pressure gradient force $\left(F_{p}\right)$ are obtained.

$$
\begin{gathered}
F_{D}=C_{D} \frac{\rho_{g}\left|v-v_{p}\right|\left(v-v_{p}\right)}{2} \frac{\pi d_{p}^{2}}{4} \\
F_{P}=-\frac{\pi d_{p}^{3}}{6} \frac{\partial p}{\partial l}
\end{gathered}
$$

where, $F_{D}$ is the drag force acting on seeds; $F_{p}$ is the pressure gradient force acting on seeds; $C_{D}$ is the drag coefficient (when $\left.R e_{p}>1000, C_{D}=0.44\right) ; \rho_{g}$ is the air density; $v$ is the airflow velocity; $v_{p}$ is the seed velocity; $d_{p}$ is the average seed diameter of $P$. notoginseng; $p$ is the outlet pressure of the air nozzle; and $l$ is the pressure distance length.

\subsection{Mechanics analysis of the seed-filling process}

In the seed box, the seed-filling process is completed mainly in the first, second and third holes. The filling force of the third hole is analyzed ${ }^{[28]}$ as shown in Figure 13.

According to the force analysis in Figure 13, the boundary conditions of the force on the seeds at the moment of filling the hole are as follows.

$$
\left\{\begin{array}{l}
f_{1}+J \cos \lambda+F_{D} \sin \lambda \leq N_{2} \sin \alpha+ \\
f_{2} \cos \alpha \\
J=m \varpi^{2} r_{p} \\
f_{1}=\mu_{1} N_{1} \\
f_{2}=\mu_{2} N_{2}
\end{array}\right.
$$


where, $F_{D}$ is the drag force acting on seeds; $J$ is the centrifugal force acting on seeds; $N_{1}$ is the supporting force of the hole wall on seeds; $N_{2}$ is the seed population support for seeds; $f_{1}$ is the rolling friction between seed and the metering wheel; $f_{2}$ is the friction of the population relative to the seed; $G$ is the seed gravity; $\lambda$ is the angle between the centerline of the hole and the wall of the hole (its value is $\theta / 2$ ); $\alpha$ is the angle between $N_{2}$ and $y ; \omega$ is the angular velocity of the metering wheel; $r_{p}$ is the radius of the metering wheel; $\mu_{1}$ is the friction coefficient between the seed and the metering wheel; and $\mu_{2}$ is the interspecific friction coefficient.

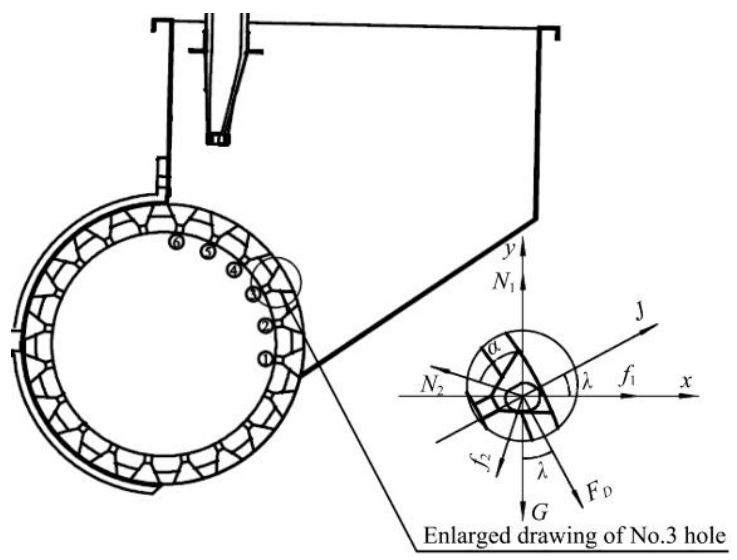

Figure 13 Force analysis of the filling process

According to Equation (12), the resultant forces of the drag force, rolling friction force and centrifugal force should be overcome in the seed-filling hole. The rolling friction force of seeds is determined by their physical characteristics and the roughness of the hole surface of the metering wheel. The surface of the hole is smooth, which is beneficial to the seed-filling effect. The centrifugal force of the seeds is proportional to the rotational speed of the metering wheel. The increase in the rotational speed and the centrifugal force is unfavorable to the seed-filling effect. The drag force of air flow on seeds is related to the air flow velocity. The lower the velocity of air flow in the filling area, the better is the seed-filling effect.

\subsection{Mechanical analysis of the seed-cleaning process}

In the seed box, the seed-cleaning process is completed mainly in the fourth and fifth holes. The seed-cleaning force of the fifth hole is analyzed as shown in Figure 14.

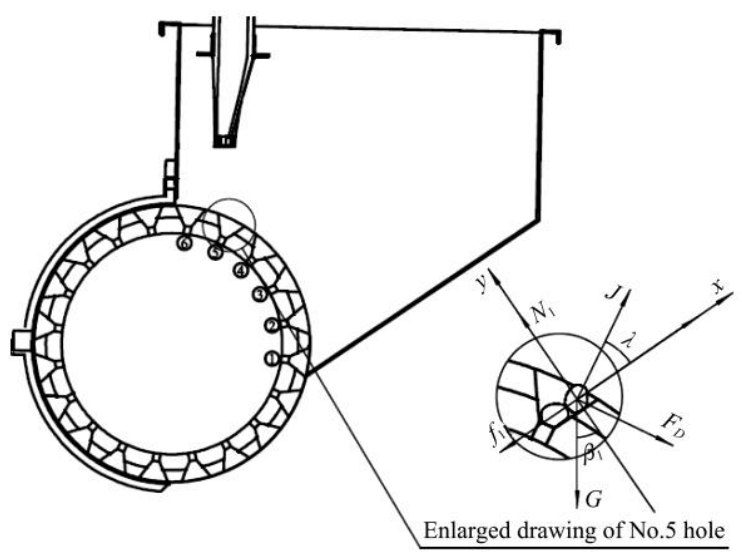

Figure 14 Force analysis of the cleaning process

According to the force analysis of Figure 14, the boundary conditions of the force on the seeds at the moment of cleaning the hole are as follows.

$$
F_{D} \sin \lambda+J \cos \lambda+N_{3} \geq G \sin \beta_{1}+f_{1}
$$

where, $\beta_{1}$ is the angle between the right edge of the hole and the horizontal direction and $N_{3}$ is the supporting power exerted by the bottom seed on the edge seed.

According to Equation (13), only when the combined force of the drag force, centrifugal force and bottom seed-supporting force is greater than the combined force of gravity and rolling friction can the seed be cleared out of the hole. Therefore, the greater the drag force on the seed in the clearing area is, the better the clearing effect; the higher the rotational speed of the metering wheel is, the greater the centrifugal force and the better the seed-cleaning effect.

\subsection{Mechanical analysis of the seed-pressing process}

In the seed box, the seed-pressing process is completed mainly in the fifth and sixth holes. The seed-pressing force of the sixth hole is analyzed as shown in Figure 15.

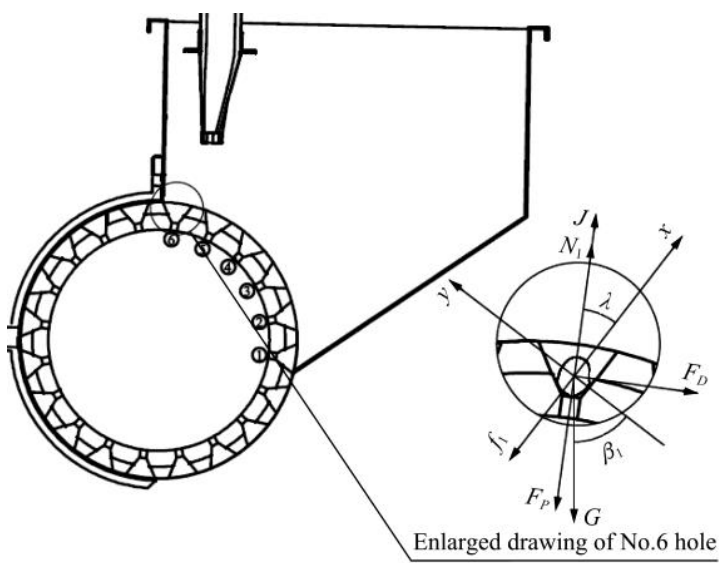

Figure 15 Force analysis of the seed-pressing process

According to Figure 15, a single seed is attached to the bottom of the hole, and its stress is as follows.

$$
f_{1}+F_{P} \cos \lambda+G \sin \beta_{1} \geq F_{D} \sin \lambda+\left(J+N_{1}\right) \cos \lambda
$$

According to Equation (14), the pressure gradient force on the seeds can be increased by increasing the air pressure of the air nozzle during seed pressing, and the effect of seed pressing can be improved. However, at the same time, the drag force on seeds is increased, which is not conducive to the effect of seed pressing. Therefore, the optimum pressure range at the outlet of the air nozzle should be sought.

The following is a combination of Equations (10)-(14):

$$
\begin{aligned}
& \operatorname{Max}\left\{G \sin \beta_{1}+\mu_{1} N_{1}-m \varpi^{2} r \cos \frac{\theta}{2}\right\} \\
& \leq 6.66 \times 10^{-6}\left(\frac{2 \sqrt{p}}{1.29}-\omega r\right)^{2} \leq \operatorname{Min}\left\{N_{2} \sin \alpha\right. \\
& \left.+\mu_{2} N_{2} \cos \alpha-m \varpi^{2} r \cos \frac{\theta}{2}-\mu_{1} N_{1}\right\}
\end{aligned}
$$

Equation (15) shows that the range of working pressure $\mathrm{P}$ is related to the angular velocity of the metering wheel and the cone angle of the hole. According to the experiment, the 1000-grain weight of $P$. notoginseng seeds is $69.77 \mathrm{~g}$, the rolling friction coefficient between $P$. notoginseng seeds and the seed-metering wheel is 0.132 , and the friction coefficient between $P$. notoginseng seeds and the seed-metering wheel is 0.05 . The forward speed of the metering wheel is $0.36-1.1 \mathrm{~m} / \mathrm{s}$, the angular speed is 6.28 $15.70 \mathrm{rad} / \mathrm{s}$, and $\beta_{1}=36^{\circ}, \beta_{2}=52^{\circ}$, and $\alpha=68^{\circ}$. The outlet pressure of the air nozzle is $0.24-0.58 \mathrm{kPa}$. Considering the complexity of the actual work of the metering device, the outlet pressure of the gas nozzle is $0.2-0.6 \mathrm{kPa}$. 


\section{Parameter optimization test of the seed-metering} device

\subsection{Testing materials and equipment/instruments}

The experimental material was $P$. notoginseng seeds from Wenshan, Yunnan Province. The moisture content of seeds was $57 \%$, and the weight of 1000 seeds was $69.77 \mathrm{~g}$. The seed-metering device was installed on a JPS-12 seed-metering device performance test bench for testing purposes. The seed bed belt moves in the same direction as the seed-metering device. The outlet pressure of the air nozzle is measured by the wind speed and wind pressure measuring instrument. The maximum diameter of the gradual expansion section (D) is $95 \mathrm{~mm}$, the angle of the gradual expansion section $\left(\mathrm{A}_{1}\right)$ is $40^{\circ}$, and the taper of the central cone $\left(\mathrm{A}_{2}\right)$ in the allotter is $45^{\circ}$. The test device is shown in Figure 16.

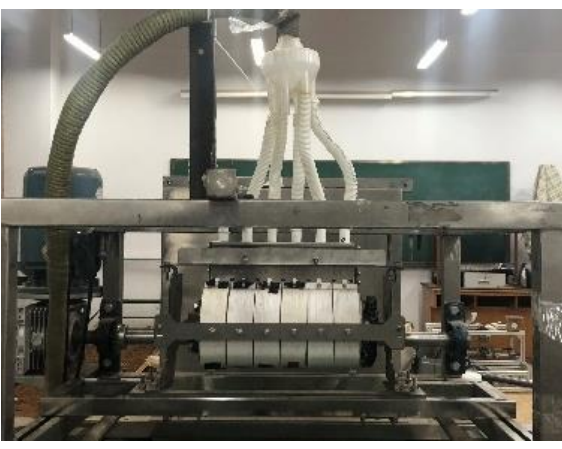

\subsection{Test method}

Figure 16 Test bench

The experiment was carried out according to the testing methods of single drills (precision drills) (GB/T6973-2005) ${ }^{[29]}$. The quadratic orthogonal rotary center combination test method was adopted. The outlet pressure of the air nozzle, the forward speed of the seed-metering device and the cone angle of the hole were selected as test factors, and the qualified index of grain spacing, the multiple index, the miss index and the coefficient of variation of the row displacement consistency were taken as test indexes ${ }^{[30]}$. The factor coding levels are shown in Table 6. Each group of experiments was repeated three times, with the average value taken as the test result. Before each test, the outlet pressure of each air nozzle was measured, and the average value was taken as the factor level.
Table 6 Levels of test factors

\begin{tabular}{cccc}
\hline \multirow{2}{*}{ Level } & \multicolumn{3}{c}{ Factor } \\
\cline { 2 - 4 } & $X_{1} / \mathrm{kPa}$ & $X_{2} / \mathrm{m}^{-1}$ & $\mathrm{~s}_{3} / \mathrm{mm}$ \\
\hline-1.682 & 0.2 & 0.36 & 45 \\
-1 & 0.28 & 0.51 & 47 \\
0 & 0.4 & 0.73 & 50 \\
1 & 0.52 & 0.95 & 53 \\
1.682 & 0.6 & 1.1 & 55 \\
\hline
\end{tabular}

\subsection{Analysis of test results}

\subsubsection{Test results}

The experimental results are shown in Table 7.

Table 7 Test results

\begin{tabular}{|c|c|c|c|c|c|c|c|}
\hline \multirow{2}{*}{ No. } & \multicolumn{3}{|c|}{ Factor level } & \multicolumn{4}{|c|}{ Results } \\
\hline & $X_{1}$ & $X_{2}$ & $X_{3}$ & $Y_{1} / \%$ & $Y_{2} / \%$ & $Y_{3} / \%$ & $Y_{4} / \%$ \\
\hline 1 & -1 & -1 & -1 & 88.18 & 3.14 & 8.68 & 6.89 \\
\hline 2 & 1 & -1 & -1 & 91.23 & 1.08 & 7.69 & 6.03 \\
\hline 3 & -1 & 1 & -1 & 87.05 & 2.17 & 10.78 & 8.87 \\
\hline 4 & 1 & 1 & -1 & 87.84 & 1.21 & 10.95 & 9.38 \\
\hline 5 & -1 & -1 & 1 & 91.59 & 7.16 & 1.25 & 6.27 \\
\hline 6 & 1 & -1 & 1 & 93.87 & 4.23 & 1.9 & 4.97 \\
\hline 7 & -1 & 1 & 1 & 87.01 & 8.24 & 4.75 & 10.23 \\
\hline 8 & 1 & 1 & 1 & 89.48 & 4.99 & 5.53 & 9.86 \\
\hline 9 & -1.682 & 0 & 0 & 88.36 & 9.57 & 2.07 & 7.21 \\
\hline 10 & 1.682 & 0 & 0 & 90.38 & 0.37 & 9.25 & 8.24 \\
\hline 11 & 0 & -1.682 & 0 & 95.25 & 3.86 & 0.89 & 3.29 \\
\hline 12 & 0 & 1.682 & 0 & 88.75 & 1.97 & 9.28 & 11.45 \\
\hline 13 & 0 & 0 & -1.682 & 88.63 & 0.85 & 10.52 & 5.39 \\
\hline 14 & 0 & 0 & 1.682 & 92.33 & 6.17 & 1.5 & 8.71 \\
\hline 15 & 0 & 0 & 0 & 94.67 & 3.15 & 2.18 & 3.27 \\
\hline 16 & 0 & 0 & 0 & 93.74 & 2.55 & 3.71 & 2.18 \\
\hline 17 & 0 & 0 & 0 & 93.87 & 2.88 & 3.25 & 5.91 \\
\hline 18 & 0 & 0 & 0 & 95.14 & 1.57 & 3.29 & 2.78 \\
\hline 19 & 0 & 0 & 0 & 93.13 & 2.79 & 4.08 & 3.19 \\
\hline 20 & 0 & 0 & 0 & 94.74 & 1.97 & 3.29 & 2.78 \\
\hline 21 & 0 & 0 & 0 & 94.65 & 2.77 & 2.58 & 3.04 \\
\hline 22 & 0 & 0 & 0 & 95.13 & 1.54 & 3.33 & 1.97 \\
\hline 23 & 0 & 0 & 0 & 93.73 & 2.68 & 3.59 & 2.85 \\
\hline
\end{tabular}

5.3.2 Model establishment and significance test

The results of the variance analysis are shown in Table 8 .

Table 8 Results of the variance analysis

\begin{tabular}{|c|c|c|c|c|c|c|c|c|c|c|c|c|c|c|c|c|c|c|c|c|}
\hline \multirow{2}{*}{ Source } & \multicolumn{5}{|c|}{ Qualified index } & \multicolumn{5}{|c|}{ Multiple index } & \multicolumn{5}{|c|}{ Miss index } & \multicolumn{5}{|c|}{$\begin{array}{l}\text { The coefficient of variation of the row } \\
\text { displacement consistency }\end{array}$} \\
\hline & $\begin{array}{l}\text { Sum of } \\
\text { squares }\end{array}$ & $\mathrm{df}$ & $\begin{array}{l}\text { Mean } \\
\text { square }\end{array}$ & $\begin{array}{c}F \\
\text { value }\end{array}$ & $p$ value & $\begin{array}{l}\text { Sum of } \\
\text { squares }\end{array}$ & $\mathrm{df}$ & $\begin{array}{l}\text { Mean } \\
\text { square }\end{array}$ & $\begin{array}{c}F \\
\text { value }\end{array}$ & $p$ value & $\begin{array}{l}\text { Sum of } \\
\text { squares }\end{array}$ & df & $\begin{array}{l}\text { Mean } \\
\text { square }\end{array}$ & $\begin{array}{c}F \\
\text { value }\end{array}$ & $p$ value & $\begin{array}{l}\text { Sum of } \\
\text { squares }\end{array}$ & df & $\begin{array}{l}\text { Mean } \\
\text { square }\end{array}$ & $\begin{array}{c}F \\
\text { value }\end{array}$ & $p$ value \\
\hline Model & 180 & 9 & 20 & 33.6 & $<0.0001^{* *}$ & 108.26 & 9 & 12.03 & 8.83 & $0.0003^{* *}$ & 222.53 & 9 & 24.73 & 10.82 & $0.0001^{* *}$ & 174.79 & 9 & 19.42 & 15.79 & $<0.0001^{* *}$ \\
\hline$X_{1}$ & 10.52 & 1 & 10.5 & 17.7 & $0.001^{* *}$ & 44.57 & 1 & 44.57 & 32.72 & $<0.0001^{* *}$ & 11.78 & 1 & 11.78 & 5.16 & $0.0408^{*}$ & 0.01 & 1 & 0.01 & 0 & 0.9451 \\
\hline$X_{2}$ & 43.67 & 1 & 43.7 & 73.3 & $<0.0001^{* *}$ & 0.35 & 1 & 0.35 & 0.26 & 0.6219 & 51.81 & 1 & 51.81 & 22.67 & $0.0004^{* * *}$ & 57.01 & 1 & 57.01 & 46.34 & $<0.0001^{* *}$ \\
\hline$X_{3}$ & 14.09 & 1 & 14.1 & 23.7 & $0.0003^{\text {** }}$ & 49.37 & 1 & 49.37 & 36.25 & $<0.0001^{* *}$ & 116.22 & 1 & 116.2 & 50.85 & $<0.0001^{* *}$ & 2.42 & 1 & 2.42 & 1.96 & 0.1846 \\
\hline$X_{1} X_{2}$ & 0.54 & 1 & 0.54 & 0.9 & 0.3603 & 0.08 & 1 & 0.08 & 0.06 & 0.8169 & 0.21 & 1 & 0.21 & 0.09 & 0.7677 & 0.66 & 1 & 0.66 & 0.54 & 0.4765 \\
\hline$X_{1} X_{3}$ & 0.1 & 1 & 0.1 & 0.17 & 0.6836 & 1.25 & 1 & 1.25 & 0.92 & 0.3559 & 0.63 & 1 & 0.63 & 0.28 & 0.6076 & 0.22 & 1 & 0.22 & 0.18 & 0.6808 \\
\hline$X_{2} X_{3}$ & 2.48 & 1 & 2.48 & 4.16 & 0.0624 & 0.9 & 1 & 0.9 & 0.66 & 0.4315 & 0.39 & 1 & 0.39 & 0.17 & 0.6857 & 1.55 & 1 & 1.55 & 1.26 & 0.2822 \\
\hline$X_{1}^{2}$ & 58.04 & 1 & 58 & 97.4 & $<0.0001^{* *}$ & 10.36 & 1 & 10.36 & 7.61 & $0.0163^{* *}$ & 14.52 & 1 & 14.52 & 6.35 & $0.0256^{* *}$ & 44.21 & 1 & 44.21 & 35.93 & $<0.0001^{* *}$ \\
\hline$X_{2}{ }^{2}$ & 15.3 & 1 & 15.3 & 25.7 & $0.0002^{* *}$ & 0.1 & 1 & 0.1 & 0.08 & 0.7866 & 9 & 1 & 9 & 3.94 & 0.0687 & 37.81 & 1 & 37.81 & 30.73 & $<0.0001^{* *}$ \\
\hline$X_{3}^{2}$ & 36.65 & 1 & 36.7 & 61.5 & $<0.0001^{* *}$ & 1.35 & 1 & 1.35 & 0.99 & 0.338 & 18.52 & 1 & 18.52 & 8.1 & $0.0137^{* *}$ & 32.46 & 1 & 32.46 & 26.39 & $0.0002^{* *}$ \\
\hline Residual & 7.74 & 13 & 0.6 & & & 17.71 & 13 & 1.36 & & & 29.71 & 13 & 2.29 & & & 15.99 & 13 & 1.23 & & \\
\hline lack of fit & 4.15 & 5 & 0.83 & 1.84 & 0.2104 & 11.22 & 5 & 2.24 & 2.77 & 0.0969 & 19.26 & 5 & 3.85 & 2.95 & 0.0843 & 5.67 & 5 & 1.13 & 0.88 & 0.5363 \\
\hline Pure error & 3.6 & 8 & 0.45 & & & 6.49 & 8 & 0.81 & & & 10.45 & 8 & 1.31 & & & 10.33 & 8 & 1.29 & & \\
\hline Corr. total & 187.8 & 22 & & & & 125.97 & 22 & & & & 252.24 & 22 & & & & 190.78 & 22 & & & \\
\hline
\end{tabular}

Note: ${ }^{* *}$ is significant at $p<0.01 ;{ }^{*}$ is significant at $p<0.05$. 
(1) Establishment of a qualified index regression model

According to the ANOVA table (Table 8), the fitting degree of the model is highly significant $(p<0.01)$, and the $\mathrm{P}$ value of the missing item of the regression model is 0.2104 , which is not significant, indicating that there are no other main factors affecting the indicators. The $\mathrm{P}$ values of the interaction terms of the outlet of the air nozzle pressure and forward velocity $\left(X_{1} X_{2}\right)$, the outlet of the air nozzle pressure and the cone angle of the hole $\left(X_{1} X_{3}\right)$ and the forward velocity and the cone angle of the hole $\left(X_{2} X_{3}\right)$ are all greater than 0.05 , indicating that the above items have no significant impact on the qualification index, while the other $\mathrm{F}$ tests are significant. The regression equation obtained after eliminating the nonsignificant factors is shown in Equation (16)

$$
\begin{aligned}
Y_{1}= & 94.33+0.88 X_{1}-1.79 X_{2}+1.02 X_{3}-1.93 X_{1}^{2}- \\
& 1.00 X_{2}^{2}-1.53 X_{3}^{2}
\end{aligned}
$$

By checking the coefficients of the regression equation, it is found that the primary and secondary factors affecting the qualified index are the forward velocity $\left(X_{2}\right)$, the cone angle of the hole $\left(X_{3}\right)$ and the outlet of the air nozzle pressure $\left(X_{I}\right)$.

(2) Establishment of the multiple index regression model

According to the ANOVA table (Table 8), the fitting degree of the model is very significant $(p<0.01)$, and the $\mathrm{P}$ value of the missing item of the regression model is 0.0969 , which is not significant, indicating that there are no other main factors affecting the indicators. The $\mathrm{P}$ values of the forward velocity $\left(X_{2}\right)$ and the interaction terms of the outlet of the air nozzle pressure and forward velocity $\left(X_{1} X_{2}\right)$, the outlet of the air nozzle pressure and the cone angle of the hole $\left(X_{1} X_{3}\right)$, the forward velocity and the cone angle of the hole $\left(X_{2} X_{3}\right)$, the outlet of the air nozzle pressure quadratic term $\left(X_{1}^{2}\right)$ and the cone angle of the hole quadratic term $\left(X_{3}^{2}\right)$ are all greater than 0.05 , indicating that the above items have no significant impact on the qualification index, while the other $F$ tests are significant. The regression equation obtained after eliminating the nonsignificant factors is shown in Equation (17).

$$
Y_{2}=2.43-1.81 X_{1}+1.90 X_{3}+0.20 X_{2}^{2}
$$

By checking the coefficients of the regression equation, it is found that the primary and secondary factors affecting the qualified index are the outlet of the air nozzle pressure $\left(X_{1}\right)$, forward velocity $\left(X_{2}\right)$ and cone angle of the hole $\left(X_{3}\right)$.

(3) Establishment of the missed index regression model

According to the ANOVA table (Table 8), the fitting degree of the model is very significant $(p<0.01)$, and the $\mathrm{P}$ value of the missing item of the regression model is 0.0843 , which is not significant, indicating that there are no other main factors affecting the indicators. The $\mathrm{P}$ values of the interaction terms of the outlet of the air nozzle pressure and forward velocity $\left(X_{1} X_{2}\right)$, the outlet of the air nozzle pressure and the cone angle of the hole $\left(X_{1} X_{3}\right)$, the forward velocity and the cone angle of the hole $\left(X_{2} X_{3}\right)$, and the outlet of the air nozzle pressure quadratic term $\left(X_{1}^{2}\right)$ are all greater than 0.05 , indicating that the above items have no significant impact on the qualification index, while the other $\mathrm{F}$ tests are significant. The regression equation obtained after eliminating the nonsignificant factors is shown in Equation (18).

$$
Y_{3}=3.82+0.93 X_{1}+1.95 X_{2}-2.92 X_{3}+0.95 X_{1}^{2}+1.07 X_{3}^{2}
$$

By checking the coefficients of the regression equation, it is found that the primary and secondary factors affecting the qualified index are the cone angle of the hole $\left(X_{3}\right)$, forward velocity $\left(X_{2}\right)$ and outlet of the air nozzle pressure $\left(X_{1}\right)$.

(4) Establishment of the coefficient of variation of the row displacement consistency regression model
According to the ANOVA table (Table 8), the fitting degree of the model is very significant $(p<0.01)$, and the $\mathrm{P}$ value of the missing item of the regression model is 0.5363 , which is not significant, indicating that there are no other main factors affecting the indicators. The $\mathrm{P}$ values of the outlet of the air nozzle pressure $\left(X_{1}\right)$, the cone angle of the hole $\left(X_{3}\right)$ and the interaction terms of the outlet of the air nozzle pressure and forward velocity $\left(X_{1} X_{2}\right)$, the outlet of the air nozzle pressure and the cone angle of the hole $\left(X_{1} X_{3}\right)$ and the forward velocity and the cone angle of the hole $\left(X_{2} X_{3}\right)$ are all greater than 0.05 , indicating that the above items have no significant impact on the qualification index, while the other $\mathrm{F}$ tests are significant. The regression equation obtained after eliminating the nonsignificant factors is shown in Equation (19).

$$
Y_{4}=3.10+2.04 X_{2}+1.67 X_{1}^{2}+1.54 X_{2}^{2}+1.43 X_{3}^{2}
$$

By checking the coefficients of the regression equation, it is found that the primary and secondary factors affecting the qualified index are the forward velocity $\left(X_{2}\right)$, the outlet of the air nozzle pressure $\left(X_{1}\right)$ and the cone angle of the hole $\left(X_{3}\right)$.

\subsection{Analysis of the effect of various factors on the performance indicators}

Design-Expert 8.0.6 was used to process the data. The dimension reduction method was used to adjust each factor to a zero level, and the influences of the interaction of the other two factors on the qualified index and the coefficient of variation of the row displacement consistency were analyzed.

\subsubsection{Influences of various factors on the qualified index}

When the cone angle of the hole is zero, the interaction between the outlet of the air nozzle pressure and the forward velocity affects the qualified index, as shown in Figure 17a. When the air nozzle pressure is $0.35-0.52 \mathrm{kPa}$ and the forward velocity is less than $0.73 \mathrm{~m} / \mathrm{s}$, the qualified index increases. When the outlet of the air nozzle pressure is constant, the qualified index decreases gradually with increasing forward velocity; when the forward velocity is constant, with increasing pressure of the air nozzle outlet, the qualified index first increases and then decreases.

When the forward velocity is zero, the interaction between the outlet of the air nozzle pressure and the cone angle of the hole affects the qualified index, as shown in Figure 17b. When the outlet of the air nozzle pressure is $0.36-0.48 \mathrm{kPa}$ and the cone angle of the hole is $48^{\circ}-53^{\circ}$, the qualified index is higher than otherwise. When the outlet of the air nozzle pressure is constant, the qualified index first increases and then decreases with increasing cone angle of the hole. When the outlet of the air nozzle pressure is constant, the qualified index first increases and then decreases with increasing air nozzle pressure.

When the outlet of the air nozzle pressure is zero, the interaction between the cone angle of the hole and the forward velocity affects the qualified index, as shown in Figure 17c. When the forward velocity is less than $0.73 \mathrm{~m} / \mathrm{s}$ and the cone angle of the hole is $49^{\circ}-54^{\circ}$, the qualified index is higher than otherwise. When the forward velocity is constant, with increasing cone angle of the hole, the qualified index shows the trend of increasing and then decreasing; when the cone angle of the hole is constant, the qualified index decreases gradually with increasing forward velocity.

5.4.2 Influences of various factors on the coefficient of variation of the row displacement consistency

When the cone angle of the hole is zero, the interaction between the outlet of the air nozzle pressure and the forward velocity affects the coefficient of variation of the row displacement 
consistency, as shown in Figure 18a. When the air nozzle pressure is $0.34-0.46 \mathrm{kPa}$ and the forward velocity is less than $0.73 \mathrm{~m} / \mathrm{s}$, the coefficient of variation of the row displacement consistency is lower than otherwise. When the outlet of the air nozzle pressure is constant, the coefficient of variation of the row displacement consistency increases gradually with increasing forward velocity; when the forward velocity is constant, with increasing outlet of the air nozzle pressure, the coefficient of variation of the row displacement consistency first decreases and then increases.

When the forward velocity is zero, the interaction between the outlet of the air nozzle pressure and the cone angle of the hole affects the coefficient of variation of the row displacement consistency, as shown in Figure 18b. When the outlet of the air nozzle pressure is $0.34-0.46 \mathrm{kPa}$ and the cone angle of the hole is $48^{\circ}-51^{\circ}$, the coefficient of variation of the row displacement consistently increases. When the outlet of the air nozzle pressure is constant, with increasing cone angle, the coefficient of variation of the row displacement consistency first decreases and then increases. When the cone angle is constant, with increasing outlet of the air nozzle pressure, the coefficient of variation of the row displacement consistency first decreases and then increases.

When the outlet of the air nozzle pressure is zero, the interaction between the cone angle of the hole and the forward velocity affects the coefficient of variation of the row displacement consistency, as shown in Figure 18c. When the forward velocity is less than $0.73 \mathrm{~m} / \mathrm{s}$ and the cone angle of the hole is $48^{\circ}-51^{\circ}$, the coefficient of variation of the row displacement consistency decreases. When the forward velocity is constant, with increasing cone angle of the hole, the coefficient of variation of the row displacement consistency first decreases and then increases. When the cone angle of the hole is constant, with increasing forward velocity, the coefficient of variation of the row displacement consistency increases.

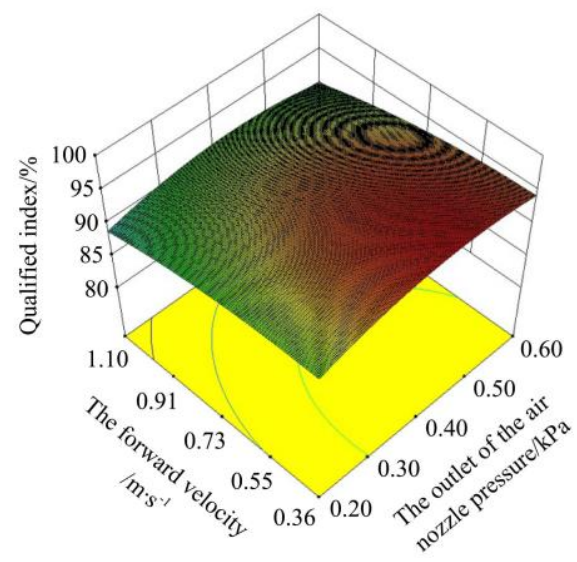

a. $Y_{1}=f\left(X_{1}, X_{2}, 0\right)$

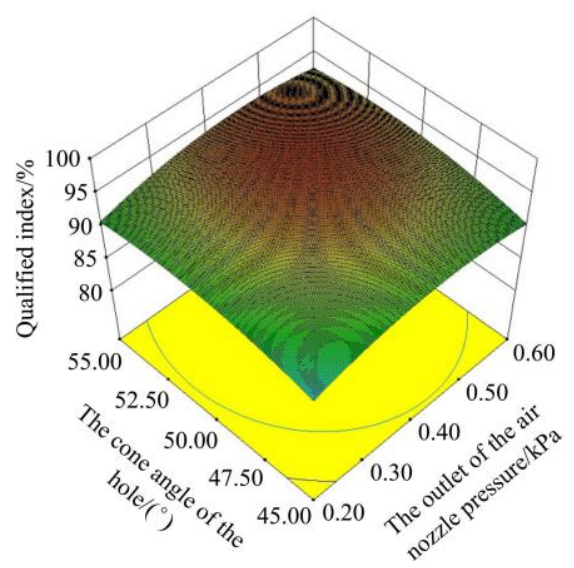

b. $Y_{1}=f\left(X_{1}, 0, X_{3}\right)$

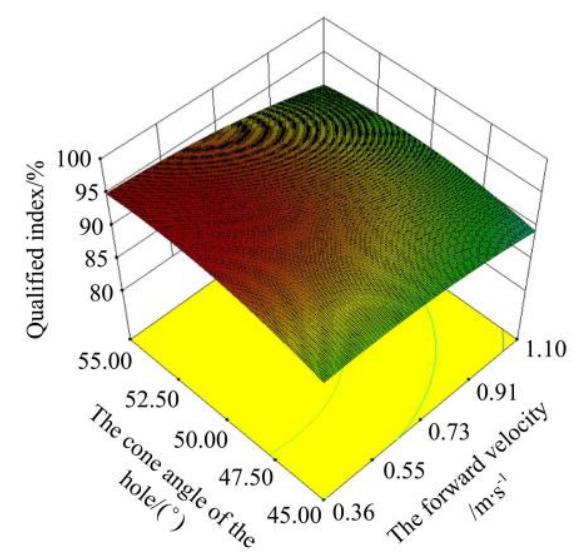

c. $Y_{1}=f\left(0, X_{2}, X_{3}\right)$

Figure 17 Effect of the interactive factors on the qualified index

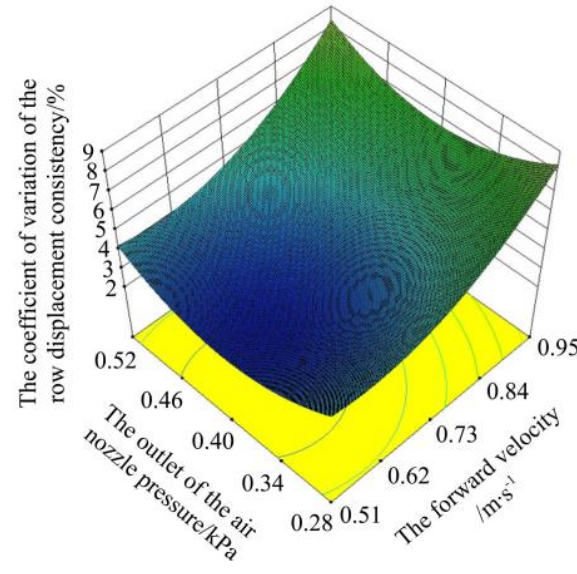

a. $Y_{2}=f\left(X_{1}, X_{2}, 0\right)$

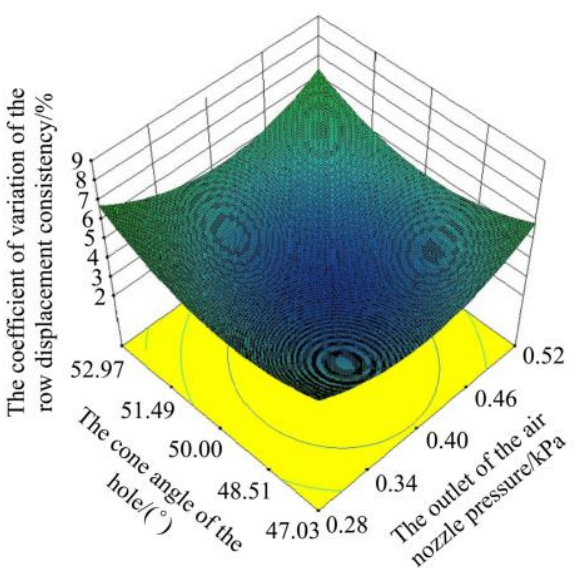

b. $Y_{2}=f\left(X_{1}, 0, X_{3}\right)$

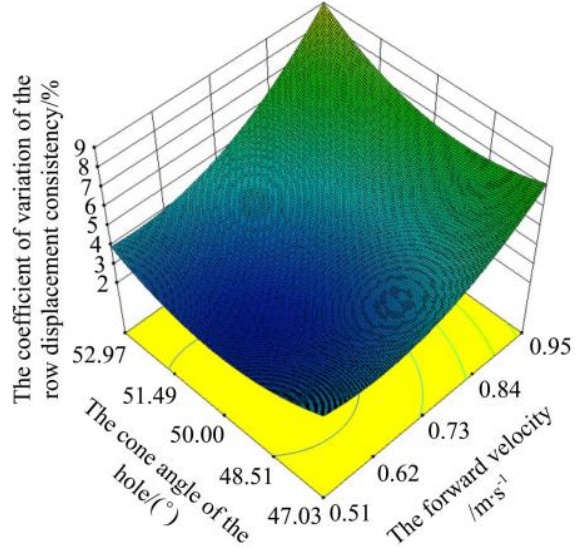

c. $Y_{2}=f\left(0, X_{2}, X_{3}\right)$

Figure 18 Effect of interactive factors on the coefficient of variation for the consistency of row displacement

\subsection{Parameter optimization and verification test}

According to the optimization principles of a high qualified index, low miss index, low multiple index and low coefficient of variation of the row displacement consistency, the parameters are optimized under the following constraints: the outlet pressure of the air nozzle is $0.2-0.6 \mathrm{kPa}$, the forward velocity is $0.36-1.1 \mathrm{~m} / \mathrm{s}$ and the cone angle of the hole is $45^{\circ}-55^{\circ}$, as shown in Figure 19 . Under the combination of parameters, the cone angle of the hole is $50^{\circ}$, the forward velocity is $0.73 \mathrm{~m} / \mathrm{s}$ and the outlet pressure of the air nozzle is $0.32-0.52 \mathrm{kPa}$; the qualified index is greater than $94 \%$, the miss index is less than $3 \%$, the multiple index is less than $5 \%$, and the coefficient of variation of the row displacement consistency is less than $5 \%$.

To verify the accuracy of the results of the optimization analysis, under the same experimental conditions, the optimum parameters (the outlet pressure of the air nozzle is $0.44 \mathrm{kPa}$, the forward velocity is $0.47 \mathrm{~m} / \mathrm{s}$ and the cone angle of the hole is $50.5^{\circ}$ ) were selected to carry out three repeated verification tests. The average value was taken as the test result, and the actual value was compared with the optimum value, as shown in Table 9. The validation test results show that the optimization results are reliable. 


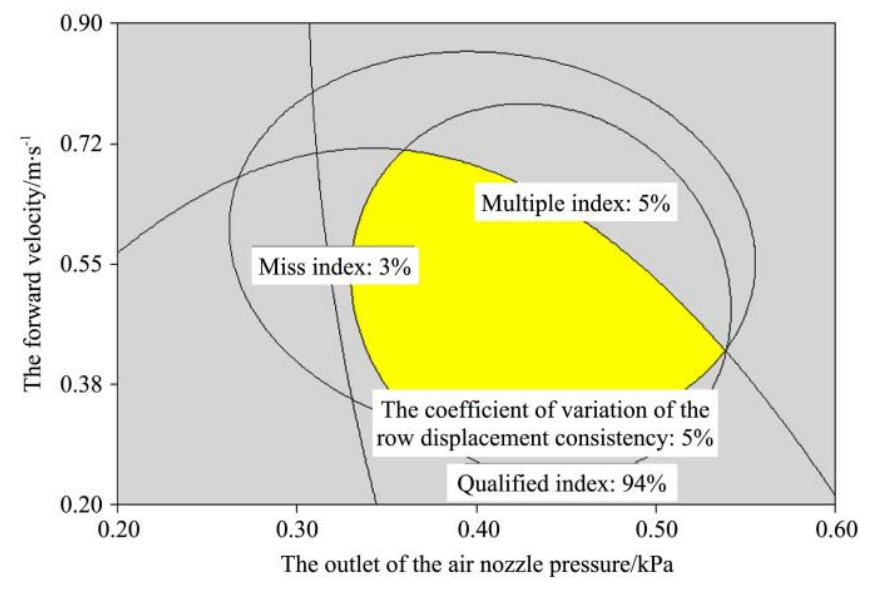

Figure 19 Parametric optimization analysis chart

Table 9 Comparison of the actual value with the optimized value

\begin{tabular}{ccccc}
\hline Type & $\begin{array}{c}\text { Qualified } \\
\text { index/\% }\end{array}$ & $\begin{array}{c}\text { Multiple } \\
\text { index/\% }\end{array}$ & $\begin{array}{c}\text { Miss } \\
\text { index/\% } \%\end{array}$ & $\begin{array}{c}\text { The coefficient of variation of the } \\
\text { row displacement consistency/\% }\end{array}$ \\
\hline $\begin{array}{c}\text { Optimization } \\
\text { value }\end{array}$ & 95.47 & 2.83 & 1.40 & 2.89 \\
Actual value & 95.02 & 2.61 & 2.37 & 3.12 \\
\hline
\end{tabular}

\section{Conclusions}

(1) Aiming at the dense planting mode of $P$. notoginseng in Wenshan, Yunnan Province, a six-row air-blowing centralized precision seed-metering device was designed, and a flow field simulation analysis of the air allotter was carried out. The simulation results show that the designed air allotter has the advantages of low pressure loss and uniform pressure at each row outlet.

(2) Three factors and five levels were used for testing based on the quadratic orthogonal rotation combination test method, and variance analysis was carried out on the test results. It was concluded that the primary and secondary factors affecting the qualified index of seed spacing were the cone angle of the hole, the outlet pressure of the air nozzle and the forward velocity.

(3) By optimizing the experimental data, the optimum parameters of the six-row air-blowing centralized precision seed-metering device are as follows: the cone angle of the hole is $50^{\circ}$, the forward velocity is less than $0.73 \mathrm{~m} / \mathrm{s}$, and the outlet pressure of the air nozzle is $0.32-0.52 \mathrm{kPa}$. Under these conditions, the qualified index is higher than $94 \%$, the miss index is less than $3 \%$, the multiple index is less than $5 \%$, and the coefficient of variation of the row displacement consistency is less than $5 \%$.

\section{Acknowledgements}

This research was supported by the National Natural Science Foundation of China (51975265, 31960366), the Key Grant Project of Yunnan Province (2018ZC001-3, 2018ZC001-4, 2018ZC001-5), and the Yunnan Province University Engineering Research Center Construction Plan Project.

\section{[References]}

[1] Mao X, Yi S J, Tao G X, Y ang L, Liu H Y, Ma Y C. Experimental study on seed-filling performance of maize bowl-tray precision seeder. Int $\mathrm{J}$ Agric \& Biol Eng, 2015; 8(2): 31-38.

[2] Yin $\mathrm{H} \mathrm{Y.} \mathrm{Research} \mathrm{on} \mathrm{the} \mathrm{development} \mathrm{of} \mathrm{domestic} \mathrm{and} \mathrm{foreign}$ pneumatic seed sowing device. Agricultural Science \& Technology and Equipment, 2013; 230(8): 25-26. (in Chinese)
[3] Zhang Z P, Ma C L, Zuo C C. The Development of the seed-metering device for precision planter and its theoretical study. Journal of Jilin University of Technology, 1995; 4: 112-117. (in Chinese)

[4] Yazgi A, Daegirmencioglu A. Optimisation of the seed spacing uniformity performance of a vacuum-type precision seeder using response surface methodology. Biosystems Engineering, 2007; 97(3): 347-356.

[5] Yazgi A, Daegirmencioglu A. Measurement of seed spacing uniformity performance of a precision metering unit as function of the number of holes on vacuum plate. Measurement, 2014; 56(10): 128-135.

[6] Zulin Z, Upadhvava S K, Shafii S, Garrett R E. Hydropneumatic seeder for primed seed. Tua-nsactions of the ASABE, 1998; 41(2): 307-314.

[7] Jia H L, Chen Y L, Zhao J L, Guo M Z, Huang D Y, Zhang J. Design and key parameter optimization of an agitated soybean seed metering device with horizontal seed filling. Int J Agric \& Biol Eng, 2018; 11(2): 76-87.

[8] Singh R C, Singh G, Saraswat D C. Optimization of design and operational parameters of a pneumatic seed metering device for planting cottonseeds. Biosystems Engineering, 2005; 92(4): 429-438.

[9] Yang S H, Sun Y J, Ma C L, Zhao H L. Optimization of parameters of air-blowing vertical-rotor type precision seed-metering device. Transactions of the CSAE, 2008; 24(2): 116-120. (in Chinese)

[10] Ma C L, Li S W. Study on improving the filling speed limit of gas blower Journal of Jilin University of Technology, 1981; 3: 28-37. (in Chinese)

[11] Hu S R, Ma C L, Li H Z, Li S W. Study on the influence of discharge frequency and air velocity of air-blowing seed meter on seed quality. Journal of Jilin University of Technology, 1981; 4: 26-35. (in Chinese)

[12] Hu S R, Ma C L, Li H Z, Li S W. Study on influence of structural parameters of cone hole of air blowing type meter on seed quality. Transactions of the CSAM, 1981; 3: 21-31. (in Chinese)

[13] Sun Y J, Ma C L, Zhang Z Y. Parameters optimization of precision seed-metering device based on uniform design. Journal of Jilin University (Engineering and Technology Edition), 2004; 4: 569-572. (in Chinese)

[14] Chen Z R, Yu J Q, Xue D M, Wang Y, Zhang Q, Ren L Q. An approach to and validation of maize-seed-assembly modelling based on the discrete element method. Powder Technololgy, 2018; 328(4): 167-183.

[15] Thang C Z, Xiang W B, Xie F P. Experimental study on the air-blown hybrid rice precision seeding device hole type. Transactions of the CSAE 1999; 15(1): 241-243.

[16] Liu J, Cui T, Zhang D X, Huang S L, Shi S. Experimental study on pressure of air-blowing precision seed-metering device. Transactions of the CSAE, 2011; 27(12): 18-22. (in Chinese)

[17] Y u J J, Liao Y T, Cong J L, Y ang S, Liao Q X. Simulation analysis and match experiment on negative and positive pressures of pneumatic precision metering device for rapeseed. Int J Agric \& Biol Eng, 2014; 7(3): 1-12.

[18] Li M, Liu X H, Liao Y T, Liao Q X. Pneumatic cylinder-type centralized precision metering device for rapeseed. Transactions of the CSAM, 2013; 44(12): 68-73. (in Chinese)

[19] Li M, Liao Q X, Liao Y T, Shu C X, Li L. Analysis on seeding process of pneumatic cylinder-type centralized rapeseed precision metering device. Transactions of the CSAE, 2014; 30(23): 17-27. (in Chinese)

[20] Lai Q H, Cao X L, Yu Q X, Sun K, Qin W. Design and experiment of precision seeding device for hole-dropplanter for panax notoginseng. Transactions of the CSAM, 2019; 50(1): 85-95. (in Chinese)

[21] Yin X W, Yang L, Zhang D X, Cui T, Han D D, Zhang T L. Design and experiment of balanceand low-loss air allotter in air pressure maize precision planter. Transactions of the CSAE, 2016; 32(19): 9-17. (in Chinese)

[22] Zhang Z S. Fluid mechanics (The Third Edition). Tsinghua University Press, 2015; pp.108-120.

[23] Zhang B P. Design principle of seeding machinery. China Machine Press, 1982. (in Chinese)

[24] Chen Z, Handbook of agricultural machinery design. China Agricultural Science and Technology Publishing House, 2007. (in Chinese)

[25] Ren C, Gao X J, Su W, Wang Z Y, Lai Q H. Experimental study on physical and mechanical characteristicsof Panax notoginseng seeds. Journal of Hunan Agricultural University (Natural Sciences), 2015; 41(1): 109-112. (in Chinese)

[26] Xing H, Wang Z M, Luo X W, Zang Y, Yang W W, Zhang M H. Design of an active seed throwing and cleaning unit for pneumatic rice seed metering device. Int J Agric \& Biol Eng, 2018; 11(2): 62-69. 
[27] Li J H. Multi-scale simulation of particle-fliud complex systems. Science Publishing Company, 2005. (in Chinese)

[28] Han D D, Zhang D X, Jing H R, Yang L, Cui T, Ding Y Q. DEM-CFD coupling simulation and optimization of an inside-filling air-blowing maize precision seed-metering device. Computers and Electronics in
Agriculture, 2018; 150(6): 426-438.

[29] GB/T 6973-2005 single (precise) test method. National Standards of the People's Republic of China. (in Chinese).

[30] Zhao X M. Test design method. Science Publishing Company, 2006. (in Chinese) 